\title{
Pharmacokinetics of Pirarubicin in Pediatric Patients
}

\author{
Kazuki NAGASAWA, * Teruyoshi YOKOYAMA, ${ }^{*}$ Noriaki OHNISHI, ${ }^{* *}$ Seigo IWAKAWA, ${ }^{* *}$ \\ Katsuhiko OKUMURA, ${ }^{* *}$ Yoshiyuki KOSAKA, ${ }^{* * *}$ Kimihiko SANO, ${ }^{* * *}$ Ryusuke \\ MURAKAMI*** and Hajime NAKAMURA***
}

Department of Hospital Pharmacy, Kyoto Pharmaceutical University, * 5 Misasaginakauchi-cho, Yamashina-ku, Kyoto 607, Japan, Department of Hospital Pharmacy, Kobe University School of Medicine, ** Kusunoki-cho, Chuou-ku, Kobe 650, Japan and Department of Pediatrics, Kobe University School of Medicine, *** Kusunoki-cho, Chuou-ku, Kobe 650, Japan

(Received October 29, 1990)

The pharmacokinetics of pirarubicin and its active metabolite, doxorubicin, were studied after intravenous administration of pirarubicin $\left(25-45 \mathrm{mg} / \mathrm{m}^{2}\right)$ to ten pediatric patients. The concentration-time curves of pirarubicin in both blood and plasma showed representative biphasic patterns. Pirarubicin concentrations decreased rapidly from 0.5 to $2 \mathrm{~h}$ after administration and then decreased slowly until $24 \mathrm{~h}$ in all subjects. High concentrations of the metabolite, doxorubicin, were detected at $0.5 \mathrm{~h}$ after administration of pirarubicin which decreased gradually until $24 \mathrm{~h}$. The area under the concentration-time curve from 0 to $24 \mathrm{~h}\left(A U C_{0-24}\right)$ of pirarubicin and doxorubicin in blood were 3-4 times higher than those in plasma, suggesting that these drugs had a high affinity for blood cells. The $A U C_{0-24}$ ratio of doxorubicin to pirarubicin in plasma was calculated to be 0.441 . It might be indicated that not only pirarubicin but also doxorubicin are responsible for the therapeutic efficacy and the incidence of toxicity of pirarubicin. The pharmacokinetics of pirarubicin in pediatric patients was fundamentally similar to that of adults, but it was recognized that considerable interindividual variation in the disposition of pirarubicin and doxorubicin exists.

Keywords — pirarubicin; doxorubicin; pharmacokinetics; pediatric patient; moment analysis

\section{Introduction}

Pirarubicin ((2" $R)-4^{\prime}$-O-tetrahydropyranyldoxorubicin, Fig. 1) is a new antitumor agent of anthracycline derivative, which was synthesized by Umezawa in 1979. ${ }^{1)}$ Pirarubicin showed strong antitumor activity both in vitro and in experimental animal tumor systmes, as well as a low incidence of cardiotoxicity and alopecia in<smiles>COc1cccc2c1C(=O)c1c(O)c3c(c(O)c1C2=O)CC(O)(C(=O)CO)CC3OC1CC(N)C2CCCC(C2)O1</smiles>

pirarubicin hamsters in comparison to doxorubicin. ${ }^{2)}$ Pirarubicin was rapidly taken up by L5178Y and L1210 cells, accumulated in the cell nuclei, and thus inhibited deoxyribonucleic acid (DNA) synthesis. ${ }^{3)}$ A faster uptake for pirarubicin than for doxorubicin or 4 '-epidoxorubicin was reported in Friend leukemia cells and may be related to its cytotoxicity.4) In clinical trials, it was shown that pirarubicin has higher clinical efficacy<smiles>COc1cccc2c1C(=O)c1c(O)c3c(c(O)c1C2=O)CC(O)(C(=O)CO)CC3OC(C)O</smiles>

Fig. 1. Chemical Structure of Drugs 
against several solid tumors, acute leukemia and malignant lymphoma. Pirarubicin also showed a lower incidence of side effects (e.g. cardiotoxicity, alopecia and gastrointestinal disorder) compared to other anthracyclines. ${ }^{5-8)}$ For these reasons, pirarubicin has recently begun to be used in pediatric patients. However, at present there are no reports on the pharmacokinetics of pirarubicin in pediatric patients, although its pharmacokinetics in adults have been reported in detail. ${ }^{9-13)}$ The purpose of this investigation is to study the pharmacokinetics of pirarubicin in pediatric patients, because it is closely associated with the therapeutic efficacy and the incidence of pirarubicin toxicity. In addition, the concentrations of both pirarubicin and doxorubicin in blood and plasma were measured simultaneously, because it was thought that high cellular uptake of these drugs was responsible for their efficacy and toxicity.

\section{Matherials and Methods}

Study Design - The ten pediatric patients enrolled in this study had been undergoing therapy for malignant diseases at the department of pediatrics of Kobe University Hospital. The clinical characteristics of the patients are individually listed in Table I. Patient No. 1 was in the induction remission period and all of the others were in the consolidation period. All patients had normal hepatic and renal function. Informed consents were obtained from patients or their parents prior to therapy.

Pirarubicin was administered to patients at a dose of $25-45 \mathrm{mg} / \mathrm{m}^{2}$ by intravenous bolus injection. Blood samples $(3 \mathrm{ml})$ were collected in heparinized disposable syringes at the following times after drug administration: $0.5,1,2,4,6$, 8,12 and $24 \mathrm{~h}$. Blood samples were centrifuged at $3000 \mathrm{rpm}$ for $5 \mathrm{~min}$ at room temperature immediately after collection and the extracted plasma fraction was stored at $-20^{\circ} \mathrm{C}$ until the time of assay. About $1 \mathrm{ml}$ of blood was also stored as blood samples.

Assay of Pirarubicin and Doxorubicin in Biological Samples — The concentrations of pirarubicin and doxorubicin in blood and plasma were determined by high performance liquid chromatography (HPLC) by a slight modification of the method of Nakajima et al. ${ }^{11)}$ Pirarubicin metabolites other than doxorubicin could

TABLE I. Patient Characteristics

\begin{tabular}{|c|c|c|c|c|c|c|c|}
\hline $\begin{array}{l}\text { Patient } \\
\text { No. }\end{array}$ & Name & Sex & $\begin{array}{l}\text { Age } \\
\text { (year) }\end{array}$ & $\begin{array}{l}\text { Weight } \\
(\mathrm{kg})\end{array}$ & $\begin{array}{c}\mathrm{BSA}^{a)} \\
\left(\mathrm{m}^{2}\right)\end{array}$ & Diagnosis & $\begin{array}{l}\text { Dose } \\
\left(\mathrm{mg} / \mathrm{m}^{2}\right)\end{array}$ \\
\hline 1 & K. H. & $\mathbf{M}$ & 2 & 15.0 & 0.6 & $\mathrm{ALL}^{b)}$ & $\begin{array}{l}\mathrm{THP}^{d \prime}(40), \mathrm{EX}^{e)}(1000), \mathrm{VP}-16^{f)}(100), \\
\mathrm{L}-\mathrm{Asp}^{g)}\left(6000 \mathrm{U} / \mathrm{m}^{2}\right)\end{array}$ \\
\hline 2 & T. F. & $\mathrm{F}$ & 5 & 18.0 & 0.7 & ALL & THP (40), VCR ${ }^{h)}(1.4)$, PSL $^{i)}$ \\
\hline 3 & K. K. & $\mathbf{M}$ & 6 & 17.6 & 0.7 & Neuroblastoma & THP (40) \\
\hline 4 & T. N. & $\mathbf{M}$ & 7 & 29.4 & 1.0 & ALL & THP (40), VCR (1.5) \\
\hline 5 & M. S. & $\mathbf{F}$ & 9 & 29.6 & 1.0 & ALL & THP (40), VCR (1.5) \\
\hline 6 & K. I. & $\mathbf{M}$ & 9 & 27.2 & 1.0 & ALL & THP (40), VCR (1.5), PSL (40) \\
\hline 7 & R. H. & $\mathbf{F}$ & 10 & 36.7 & 1.1 & $\begin{array}{l}\text { Lympho- } \\
\text { epithelioma }\end{array}$ & $\begin{array}{l}\text { THP (40), EX (600), VCR (1.2), } \text { BLM }^{j}(4) \text {, } \\
\text { PSL (40) }\end{array}$ \\
\hline 8 & K. N. & $\mathbf{M}$ & 13 & 47.2 & 1.4 & $\begin{array}{l}\text { Malignant } \\
\text { lymphoma }\end{array}$ & THP (45), EX (1000), VCR (1.5), PSL (40) \\
\hline 9 & S. F. & $\mathbf{M}$ & 14 & 42.0 & 1.4 & $\mathrm{AML}^{c)}$ & THP (25), Ara-C ${ }^{k \prime}(200), 6-\mathrm{MP}^{\prime \prime}$ \\
\hline 10 & M. H. & $\mathbf{F}$ & 16 & 47.6 & 1.5 & ALL & THP (30), VCR (1.4), PSL (60) \\
\hline & Mean & & 9.1 & 31.0 & 1.0 & & 38.0 (THP) \\
\hline & S.D. & & 4.3 & 12.1 & 0.3 & & 5.9 \\
\hline
\end{tabular}

a) BSA, body surface area; b) ALL, acute lymphoblastic leukemia; c) AML, acute myeloid leukemia; $d$ ) THP, pirarubicin; e) EX, cyclophosphamide; f) VP-16, etoposide; $g$ ) L-Asp, L-asparaginase; $h$ ) VCR, vincristine; i) PSL, prednisolone; j) BLM, bleomycin; $k$ ) Ara-C, cytosine arabinoside; l) 6-MP, 6-mercaptopurine. 
not be measured because no pure standards were available. The chromatographic system consisted of a Shimadzu LC-6A equipped with a fluorescence detector (Shimadzu, RF-535). The analytical conditions were as follows: The column was a STR ODS-M $(5 \mu \mathrm{m}, 250 \mathrm{~mm} \times$ $4 \mathrm{~mm}$ i.d., Shimadzu), with a mobile phase consisting of acetonitrile- $0.2 \mathrm{M}$ acetic acidammonium formate buffer, $\mathrm{pH} 4.0,(30: 70$; v/v) and a flow rate of $0.7 \mathrm{ml} / \mathrm{min}$. Fluorescence was measured at $470 \mathrm{~nm}$ (excitation) and at $550 \mathrm{~nm}$ (emission). The analysis was carried out at $22{ }^{\circ} \mathrm{C}$ for a good separation and reasonably quick operation. To each $1 \mathrm{ml}$ of blood or plasma, $3 \mathrm{ml}$ $0.1 \mathrm{M}$ ammonia-ammonium chloride buffer $(\mathrm{pH}$ 9.5), $20 \mathrm{ng}$ daunorubicin as internal standard, and $13.5 \mathrm{ml}$ of a chloroform-methanol (2:1 ; $\mathrm{v} / \mathrm{v})$ mixture were added and then shaken mechanically for $30 \mathrm{~min}$. After centrifugation at $3000 \mathrm{~g}$ for $10 \mathrm{~min}$, the organic layer was collected. Nine $\mathrm{ml}$ of chloroform was added to the aqueous layer for a second extraction. The first and second organic layers were combined and evaporated to dryness at $30{ }^{\circ} \mathrm{C}$ under $\mathrm{N}_{2}$ stream. The residue was dissolved in $3 \mathrm{ml}$ of a chloroform-methanol $(2: 1 ; \mathrm{v} / \mathrm{v})$ mixture. After evaporation of the mixture, the residue was dis-

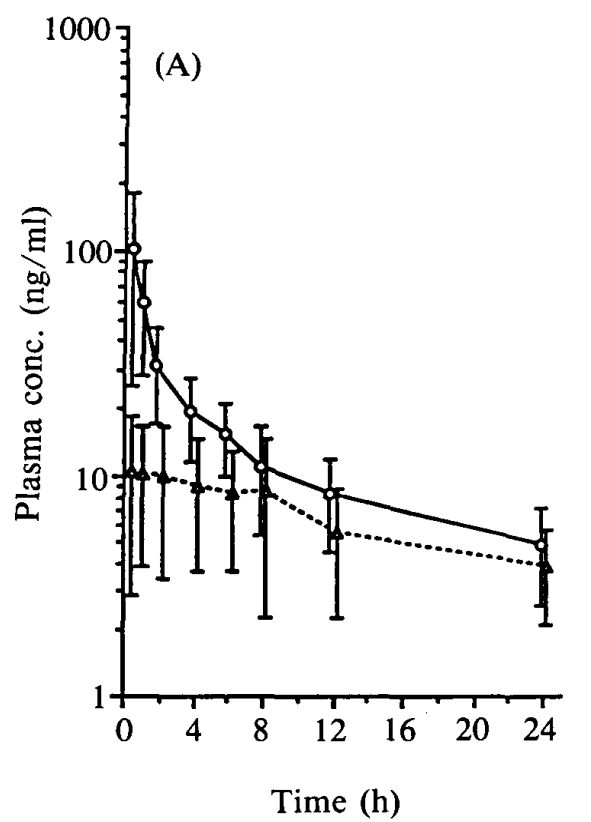

solved in $0.3 \mathrm{ml}$ mobile phase. A $75 \mu$ l portion of the supernatant obtained by centrifugation at $10000 \mathrm{~g}$ for $1 \mathrm{~min}$ was injected into the HPLC column. The retention times under these conditions were 7.7, 16.2 and $24.1 \mathrm{~min}$ for doxorubicin, daunorubicin and pirarubicin, respectively. No interference peaks due to endogenous substances were observed in either blood or plasma obtained from the ten patients. The ratios of the peak height of each drug to that of the internal standard were plotted against the known concentration of drug, and the standard curves were generated by least-squares linear regression analysis. The standard curves obtained for pirarubicin and doxorubicin were linear over the concentrations of $10-100 \mathrm{ng} / \mathrm{ml}$ in blood and plasma $(r>0.999)$. The detection limit was generally $0.5 \mathrm{ng} / \mathrm{ml}$ and coefficient of variation(CV) was less than $7.63 \%$.

Pharmacokinetic Analysis - A two compartment model was used to describe the pharmacokinetics of pirarubicin after intravenous administration in pediatric patients. Area under the concentration-time curve $(A U C)$ from 0 to $24 \mathrm{~h}$ was calculated by the trapezoidal rule for pirarubicin and doxorubicin. The pirarubicin $A U C$ from 24 to infinity was calculated using the

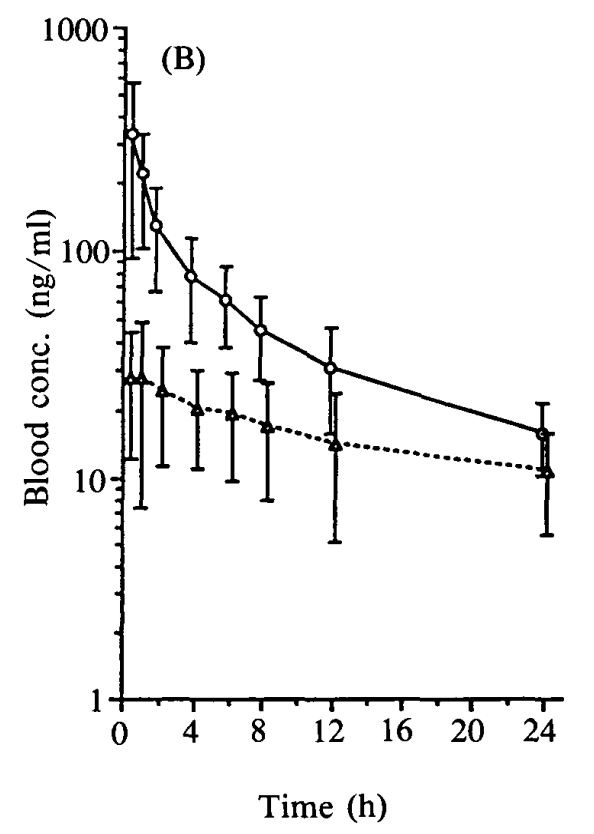

Fig. 2. Time Courses of Pirarubicin $(O)$ and Its Metabolite, Doxorubicin $(\Delta)$, in Plasma (A) and Blood (B) after Intravenous Administration of Pirarubicin $\left(40 \mathrm{mg} / \mathrm{m}^{2}\right)$ to 7 Pediatric Patients

Each point represents the mean \pm S.D. of $6-7$ patients. 


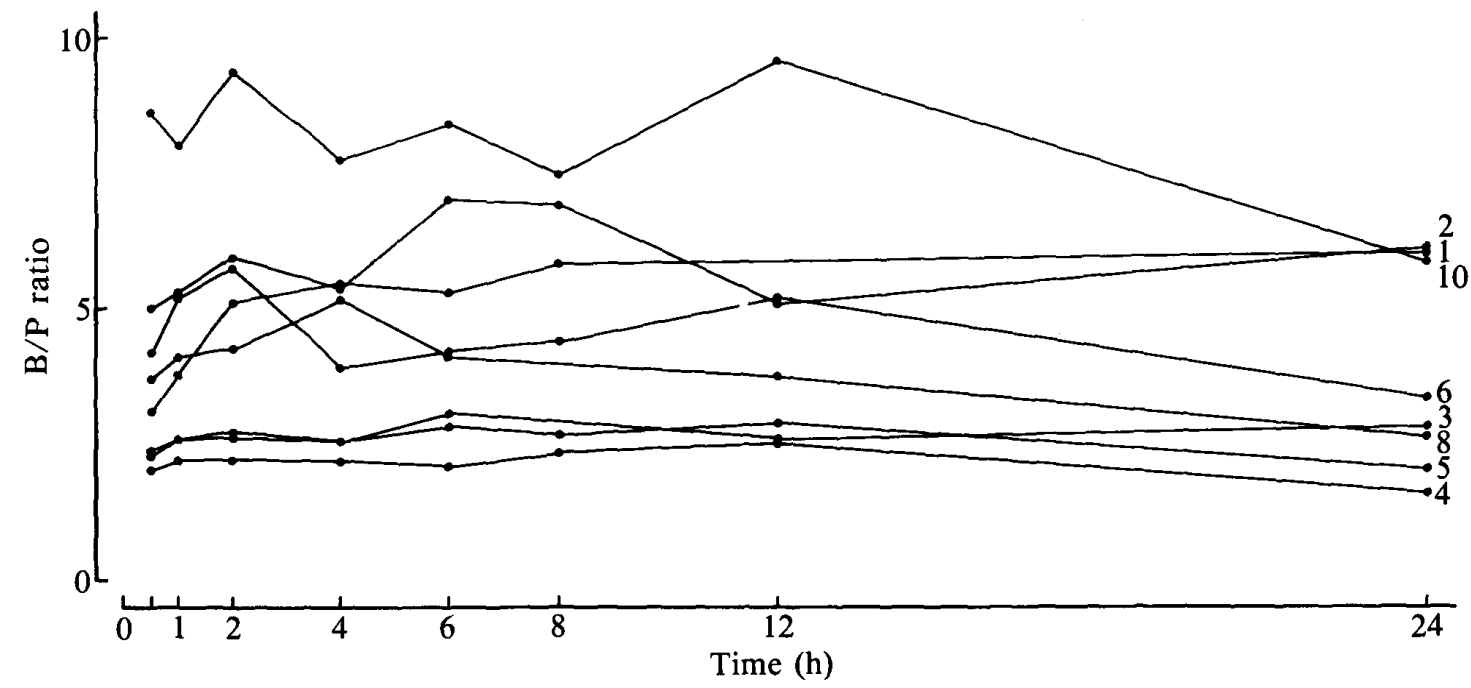

Fig. 3. The Time Courses for Blood to Plasma Concentration (B/P) Ratio of Pirarubicin for Each Patient Each number represents the patient number.

slope obtained from least-square regression of the terminal phase. Pharmacokinetic parameters in the compartment model analysis were calculated using the program MULTI ${ }^{14)}$ of the nonlinear, least-square method. The data are weighted by unity (weight $=1 / \mathrm{C}^{2}$ ) in all calculations of the present study.

Statistical Analysis - The data are expressed as mean \pm S.D. and CV. Comparisons between the two groups were performed by means of an unpaired $t$-test corrected for unequal variance. A statistically significant difference between groups was defined as a $p$ value of 0.05 or less.

\section{Results}

The time courses of pirarubicin and its

TABLE II. Pharmacokinetic Parameters of Pirarubicin Determined by Moment Analysis

\begin{tabular}{|c|c|c|c|c|c|c|c|c|c|c|}
\hline \multirow[b]{2}{*}{$\begin{array}{l}\text { Patient } \\
\text { No. }\end{array}$} & \multicolumn{5}{|c|}{ Plasma } & \multicolumn{5}{|c|}{ Blood } \\
\hline & $\begin{array}{c}A U C_{0-24} \\
(\mathrm{ng} \cdot \mathrm{h} / \mathrm{ml}) \\
\left(\mathrm{mg} / \mathrm{m}^{2}\right)\end{array}$ & $\begin{array}{c}A U C_{0-\infty} \\
/(\mathrm{ng} \cdot \mathrm{h} / \mathrm{ml}) / \\
\left(\mathrm{mg} / \mathrm{m}^{2}\right)\end{array}$ & $\begin{array}{l}\text { MRT } \\
\text { (h) }\end{array}$ & $\begin{array}{c}\mathrm{CL}_{\mathrm{tot}} \\
\left(\mathrm{l} / \mathrm{h} / \mathrm{m}^{2}\right)\end{array}$ & $\begin{array}{c}V_{s s} \\
\left(1 / \mathrm{m}^{2}\right)\end{array}$ & $\begin{array}{c}A U C_{0-24} \\
(\mathrm{ng} \cdot \mathrm{h} / \mathrm{ml}) \\
\left(\mathrm{mg} / \mathrm{m}^{2}\right)\end{array}$ & $\begin{array}{c}A U C_{0-\infty} \\
/(\mathrm{ng} \cdot \mathrm{h} / \mathrm{ml}) / \\
\left(\mathrm{mg} / \mathrm{m}^{2}\right)\end{array}$ & $\begin{array}{l}\text { MRT } \\
\text { (h) }\end{array}$ & $\begin{array}{c}\mathrm{CL}_{\text {tot }} \\
\left(1 / \mathrm{h} / \mathrm{m}^{2}\right)\end{array}$ & $\begin{array}{c}V_{\mathrm{ss}} \\
\left(1 / \mathrm{m}^{2}\right)\end{array}$ \\
\hline 1 & 14.31 & 14.83 & 4.47 & 70.2 & 314.3 & 60.0 & 63.3 & 6.07 & 16.5 & 99.9 \\
\hline 2 & 5.24 & 6.36 & 12.50 & 154.5 & 1931.1 & 29.4 & 34.5 & 11.20 & 28.5 & 319.0 \\
\hline 3 & 8.58 & 10.64 & 13.53 & 100.7 & 1362.1 & 22.9 & 28.7 & 13.92 & 37.4 & 519.9 \\
\hline 4 & 6.29 & 7.46 & 11.15 & 134.0 & 1493.8 & 13.4 & 15.0 & 9.11 & 66.7 & 607.4 \\
\hline 5 & 21.01 & 24.29 & 9.58 & 41.2 & 394.3 & 44.9 & 50.7 & 9.28 & 19.7 & 182.9 \\
\hline 6 & 9.89 & 12.13 & 12.93 & 82.5 & 1066.1 & 44.2 & 52.4 & 11.71 & 19.1 & 223.3 \\
\hline 7 & 6.07 & 7.84 & 15.00 & 115.9 & 1738.5 & - & - & - & - & - \\
\hline 8 & 8.51 & 10.59 & 13.84 & 97.4 & 1348.0 & 33.1 & 37.3 & 10.09 & 27.7 & 279.0 \\
\hline 9 & - & - & - & - & - & 16.8 & 23.8 & 19.33 & 42.0 & 812.3 \\
\hline 10 & 5.96 & 7.77 & 15.52 & 128.7 & 1997.6 & 48.8 & 55.7 & 10.35 & 18.0 & 185.8 \\
\hline Mean & 9.54 & 11.32 & 12.06 & 102.8 & 1294.0 & $34.8^{a)}$ & $40.2^{a j}$ & 11.23 & 30.6 & 358.8 \\
\hline S.D. & 5.13 & 5.55 & 3.38 & 35.0 & 609.0 & 15.7 & 16.3 & 3.71 & 16.2 & 236.5 \\
\hline $\mathrm{CV}$ & 53.7 & 49.0 & 28.3 & 34.0 & 47.1 & 45.1 & 40.5 & 33.0 & 53.0 & 65.9 \\
\hline
\end{tabular}

a) $p<0.001$ significantly different from plasma values, respectively. 
TABLE III. $A U C_{0-24}$ of Doxorubicin and Ratio of Doxorubicin to Pirarubicin $A U C_{0-24}$

\begin{tabular}{lccccc}
\hline \hline & \multicolumn{2}{c}{ Plasma } & & \multicolumn{2}{c}{ Blood } \\
\cline { 2 - 3 } \cline { 5 - 6 } Patient No. & $\begin{array}{c}A U C_{0-24} \\
(\mathrm{ng} \cdot \mathrm{h} / \mathrm{ml}) /\left(\mathrm{mg} / \mathrm{m}^{2}\right)\end{array}$ & Ratio & & $\begin{array}{c}A U C_{0-24} \\
(\mathrm{ng} \cdot \mathrm{h} / \mathrm{ml}) /\left(\mathrm{mg} / \mathrm{m}^{2}\right)\end{array}$ & Ratio \\
\hline 1 & 6.37 & 0.513 & & 10.61 & 0.204 \\
2 & 1.56 & 0.341 & & 6.49 & 0.255 \\
3 & 5.40 & 0.726 & & 8.90 & 0.447 \\
4 & 2.70 & 0.494 & & 4.51 & 0.390 \\
5 & 7.55 & 0.414 & & 8.89 & 0.228 \\
6 & 2.53 & 0.295 & & 18.84 & 0.492 \\
7 & 2.54 & 0.483 & & - \\
8 & 2.62 & 0.356 & & 6.87 & 0.240 \\
9 & - & - & 6.20 & 0.425 \\
10 & 1.79 & 0.346 & & 9.56 & 0.226 \\
& & & & \\
Mean & 3.67 & 0.441 & & $8.98^{a)}$ & 0.323 \\
S.D. & 2.18 & 0.132 & 4.16 & 0.113 \\
CV & 59.3 & 29.9 & 46.3 & 35.1 \\
\hline
\end{tabular}

Ratio, the ratio of the $A U C_{0-24}$ of doxorubicin to the $A U C_{0-24}$ of pirarubicin. a) $p<0.01$ significantly different from plasma value.

TABle IV. Pharmacokinetic Parameters of Pirarubicin in Plasma

\begin{tabular}{lccccccc}
\hline \hline Patient No. & $\begin{array}{c}V_{1} \\
\left(1 / \mathrm{m}^{2}\right)\end{array}$ & $\begin{array}{c}V_{2} \\
\left(1 / \mathrm{m}^{2}\right)\end{array}$ & $\begin{array}{c}k_{12} \\
\left(\mathrm{~h}^{-1}\right)\end{array}$ & $\begin{array}{c}k_{21} \\
\left(\mathrm{~h}^{-1}\right)\end{array}$ & $\begin{array}{c}k_{\text {el }} \\
\left(\mathrm{h}^{-1}\right)\end{array}$ & $\begin{array}{c}t_{1 / 2(\alpha)} \\
(\mathrm{h})\end{array}$ & $\begin{array}{c}t_{1 / 2(\beta)} \\
(\mathrm{h})\end{array}$ \\
\hline 1 & 84.3 & 318.9 & 0.740 & 0.196 & 0.870 & 0.405 & 6.94 \\
2 & 798.7 & 1517.7 & 0.252 & 0.133 & 0.192 & 1.31 & 14.3 \\
3 & 476.8 & 1050.9 & 0.642 & 0.291 & 0.205 & 0.642 & 12.6 \\
4 & 513.7 & 1454.1 & 0.356 & 0.126 & 0.253 & 1.01 & 15.0 \\
5 & 175.8 & 504.3 & 0.492 & 0.171 & 0.287 & 0.774 & 12.6 \\
6 & 318.2 & 997.9 & 0.667 & 0.213 & 0.252 & 0.642 & 14.0 \\
7 & 563.8 & 1515.0 & 0.410 & 0.153 & 0.198 & 0.964 & 16.5 \\
8 & 402.2 & 1079.5 & 1.14 & 0.424 & 0.242 & 0.396 & 11.8 \\
9 & - & - & - & - & - & - & - \\
10 & 653.1 & 1374.1 & 0.458 & 0.218 & 0.210 & 0.834 & 12.6 \\
& & & & & & & \\
Mean & 443.0 & 1090.3 & 0.573 & 0.214 & 0.301 & 0.775 & 12.9 \\
S.D. & 226.0 & 436.5 & 0.264 & 0.094 & 0.216 & 0.295 & 2.68 \\
CV & 51.0 & 40.0 & 46.2 & 43.8 & 71.7 & 38.1 & 20.8 \\
\hline
\end{tabular}

metabolite, doxorubicin, in plasma and blood after intravenous administration of pirarubicin $(40$ $\mathrm{mg} / \mathrm{m}^{2}$ ) to seven pediatric patients are shown in Fig. 2. In patients No. 7 and 9 , the concentrations were measured only in plasma and blood, respectively, owing to the small volume of blood obtained and hemolysis of the blood cells. The concentrations of pirarubicin in plasma and blood-time curves showed representative biphasic patterns that decreased rapidly from 0.5 to 2 $\mathrm{h}$ after administration and then decreased gradually until $24 \mathrm{~h}$ in all patients. High concentrations of doxorubicin were detected at $0.5 \mathrm{~h}$ after administration of pirarubicin and these decayed slowly until $24 \mathrm{~h}$ in all patients. The concentrations of pirarubicin and doxorubicin in blood 
TABle V. Pharmacokinetic Parameters of Pirarubicin in Blood

\begin{tabular}{lccccccc}
\hline \hline Patient No. & $\begin{array}{c}V_{1} \\
\left(1 / \mathrm{m}^{2}\right)\end{array}$ & $\begin{array}{c}V_{2} \\
\left(1 / \mathrm{m}^{2}\right)\end{array}$ & $\begin{array}{c}k_{12} \\
\left(\mathrm{~h}^{-1}\right)\end{array}$ & $\begin{array}{c}k_{21} \\
\left(\mathrm{~h}^{-1}\right)\end{array}$ & $\begin{array}{c}k_{\text {el }} \\
\left(\mathrm{h}^{-1}\right)\end{array}$ & $\begin{array}{c}t_{1 / 2(\alpha)} \\
(\mathrm{h})\end{array}$ & $\begin{array}{c}t_{1 / 2(\beta)} \\
(\mathrm{h})\end{array}$ \\
\hline 1 & 35.9 & 90.9 & 0.619 & 0.247 & 0.470 & 0.559 & 7.43 \\
2 & 171.1 & 271.1 & 0.174 & 0.110 & 0.150 & 1.77 & 16.5 \\
3 & 214.9 & 376.4 & 0.498 & 0.284 & 0.168 & 0.773 & 13.0 \\
4 & 200.8 & 456.2 & 0.475 & 0.209 & 0.332 & 0.735 & 9.40 \\
5 & 70.5 & 154.2 & 0.507 & 0.231 & 0.303 & 0.715 & 9.57 \\
6 & 81.6 & 174.6 & 0.415 & 0.194 & 0.236 & 0.879 & 11.9 \\
7 & - & - & - & - & - & - & - \\
8 & 93.0 & 202.4 & 1.48 & 0.680 & 0.299 & 2.92 & 8.08 \\
9 & 21.5 & 621.8 & 0.357 & 0.121 & 0.185 & 1.11 & 19.4 \\
10 & 75.3 & 119.6 & 0.440 & 0.277 & 0.256 & 0.775 & 8.73 \\
& & & & & & & 1.14 \\
Mean & 128.3 & 274.1 & 0.552 & 0.261 & 0.267 & 0.75 \\
S.D. & 70.4 & 177.3 & 0.369 & 0.168 & 0.099 & 0.757 & 4.09 \\
CV & 54.8 & 64.7 & 66.9 & 64.4 & 37.3 & 66.6 & 35.4 \\
\hline
\end{tabular}

were higher than those in plasma at all time points. Figure 3 showed the time courses for blood to plasma concentration $(\mathrm{B} / \mathrm{P})$ ratio of pirarubicin for each patient. The $\mathrm{B} / \mathrm{P}$ ratio for each patient was approximately constant until 24 h. However, large interindividual variations of the $\mathrm{B} / \mathrm{P}$ ratio were observed. $A U C_{0-24}, A U C_{0-\infty}$, mean residence time (MRT), total clearance $\left(\mathrm{CL}_{\text {tot }}\right)$ and distribution volume at steady state $\left(V_{\mathrm{ss}}\right)$ of pirarubicin after administration of pirarubicin in individual patients are shown in Table II. $A U C_{0-24}$ and $A U C_{0-\infty}$ in blood was significantly greater than those in plasma $(p<0.001$, respectively). MRT of pirarubicin in blood was almost equal to that in plasma. $\mathrm{CL}_{\text {tot }}$ of pirarubicin based on plasma or blood concentration was $102.81 / \mathrm{h} / \mathrm{m}^{2}$ or $30.59 \mathrm{1} / \mathrm{h} / \mathrm{m}^{2}$, respectively.

Table III shows the $A U C_{0-24}$ of doxorubicin and the $A U C_{0-24}$ ratio of doxorubicin to pirarubicin (these $A U C_{0-24}$ were corrected by the molecular weight of pirarubicin or doxorubicin). The $A U C_{0-24}$ of doxorubicin in blood were larger than those in plasma as was the case with pirarubicin. The $A U C_{0-24}$ ratio of doxorubicin to pirarubicin in plasma was 0.441 and that in blood was 0.323 . Thus, there was no statistical difference between plasma and blood in the $A U C_{0-24}$ ratio.

The time courses of pirarubicin in plasma and blood after intravenous administration of pirarubicin in pediatric patients is described by a two compartment model. Table IV and V show the pharmacokinetic parameters of pirarubicin in plasma and blood, respectively. The distribution volumes $\left(V_{2}\right)$ of the peripheral compartments of pirarubicin in both plasma and blood were about 2 -fold larger than the distribution volumes $\left(V_{1}\right)$ of the central compartments. Regarding distribution rate constants $\left(k_{12}\right.$ and $\left.k_{21}\right)$ of pirarubicin in plasma and blood, $k_{12} \mathrm{~s}$ were about 2 times greater than $k_{21} \mathrm{~s}$. Elimination rate constants in plasma and blood were approximately equal. Half-lives $\left(t_{1 / 2} \mathrm{~s}\right)$ of the $\alpha$ phase of pirarubicin in plasma and blood were 0.775 and 1.14 $\mathrm{h}$, and the $\beta$ phase $t_{1 / 2} \mathrm{~s}$ were 12.9 and $11.6 \mathrm{~h}$, respectively. In this study, considerable interindividual variation was noted in all pharmacokinetic parameters as shown in the $\mathrm{CV}$ values.

\section{Discussion}

Several antitumor agents have shown agerelated differences in pharmacokinetics, including alterations of distribution volume, or hepatic and renal clearances. ${ }^{15)}$ For example, the mean systemic clearance of doxorubicin in children is almost 3 times greater than that in adults. ${ }^{16)}$ The concentrations of pirarubicin and its active metabolite, doxorubicin, in blood were 
always found to be higher than those in plasma, as shown in Fig. 2. This result suggested that pirarubicin and doxorubicin were highly taken up by blood cells. Although there was no change on the $\mathrm{B} / \mathrm{P}$ ratio of pirarubicin until $24 \mathrm{~h}$ in each patient, large differences of these values were observed in individual subjects, as shown in Fig. 3. It was pointed out that there were large individual variations in the uptake of pirarubicin by blood cells. In addition, the uptake of pirarubicin by blood cells may be divided into three groups. Since the high concentrations of doxorubicin were detected at $0.5 \mathrm{~h}$ after administration of pirarubicin and decreased more slowly, it appeared that the biotransformation of pirarubicin to doxorubicin was very rapid, and that doxorubicin was retained in the body for a longer period of time than pirarubicin. The $A U C_{0-24}$ of pirarubicin in blood was about 3-fold that in plasma $(p<0.01)$, which may indicate that pirarubicin is easily taken up by blood cells, especially the buffy coat: white blood cells, similar to that reported in adults. ${ }^{9-13)}$ In this study, $\mathrm{CL}_{\text {tot }}$ of pediatric patients based on plasma concentration was $102.8 \mathrm{l} / \mathrm{h} / \mathrm{m}^{2}$ or $3.58 \mathrm{l} / \mathrm{h} / \mathrm{kg}$ as shown in Table II. $\mathrm{CL}_{\text {tot }}$ in adults as reported by Miller et al. ${ }^{9)}$ was $115 \mathrm{l} / \mathrm{h} / \mathrm{m}^{2}, 90.4 \mathrm{l} / \mathrm{h} / \mathrm{m}^{2}$ by Robert et $a l .{ }^{13)}$ and $3.061 / \mathrm{h} / \mathrm{kg}$ by Fujiwara. ${ }^{12)}$ Therefore, the $\mathrm{CL}_{\text {tot }}$ of pediatric patients in this study agreed approximately with that of adults. However, Majima et al. ${ }^{10}$ ) reported that $\mathrm{CL}_{\text {tot }}$ in adults was $5.96 \mathrm{1} / \mathrm{h} / \mathrm{kg}$, which is about 2 times greater than that of the pediatric patients. Majima et al. measured pirarubicin concentrations until $8 \mathrm{~h}$ after drug administration and the terminal phase $t_{1 / 2}(5.11$ h) was about a half that of the other reports. This probably accounts for why the $\mathrm{CL}_{\text {tot }}$ obtained from their values was greater than those in other reports. It was reported by Nakajima et al. ${ }^{11)}$ that $\mathrm{CL}_{\text {tot }}$ in adults was $46.1 \mathrm{l} / \mathrm{h} /$ body. This value was calculated to be $34.9 \mathrm{l} / \mathrm{h} / \mathrm{m}^{2}$ or 1.06 $\mathrm{l} / \mathrm{h} / \mathrm{kg}$, which is about a third of the value in pediatric patients. We can't clearly say from this study whether this discrepancy was due to a difference between pediatric patients and adults or differences in study conditions. The $V_{\text {ss }}$ based on plasma concentration which was 1294.0 $1 / \mathrm{m}^{2}$ in this study was comparable to the results in adults. ${ }^{13)}$ As shown in Table II, the MRT of pirarubicin in blood equaled that in plasma. However, the $A U C_{0-\infty}$ of doxorubicin couldn't be obtained because of large variations between the concentrations measured in individual subjects. The ratios of the $A U C_{0-24}$ of doxorubicin to that of pirarubicin were 0.323 in blood and 0.441 in plasma (Table III). It was therefore suggested that doxorubicin also participated in the efficacy an toxicity of pirarubicin. It was also indicated that there may be large interindividual variations in the uptake of pirarubicin and doxorubicin by blood cells, because there were great variations in the ratio of $A U C_{0-24}$ in plasma and blood. This hypothesis was supported by the results of $\mathrm{B} / \mathrm{P}$ ratio as shown in Fig. 3. However, it was not clear whether the individual variation of cellular uptake of pirarubicin was based on the age, sex or coadministration of the drug.

There are several reports on the pharmacokinetic analysis of pirarubicin. These other investigators $^{9-12}$ have analysed the time course of pirarubicin using a three compartment model because the profile of pirarubicin showed a triphasic pattern. In these studies the $t_{1 / 2}$ of the first $(\alpha)$-phase was reported to be much shorter (about $0.04 \mathrm{~h}$ ). However, it is clinically impossible, especially in pediatric patients, to detect this first-phase exactly, because it requires frequent collection of blood samples. On the other hand, Pinedo ${ }^{17)}$ stated that a two compartment model would provide much available information for clinical treatment although the pharmacokinetics of doxorubicin had been analysed by using a three compartment model. In fact, Robert et $a l$. have analysed pirarubicin pharmacokinetics using a two compartment model. ${ }^{13)}$ Therefore, in the present study, a two compartment model was used for the analysis of the pharmacokinetics of pirarubicin. In addition, the $\alpha$ and $\beta$ phases in this model may correspond to the $\beta$ and $\gamma$ phases in a three compartment model, respectively.

The $V_{2}$ was about 2-fold larger than the $V_{1}$ in both plasma and blood, indicating that pirarubicin had high cellular uptake. The $V_{2}$ value in plasma was $1090.31 / \mathrm{m}^{2}$ or $37.5 \mathrm{l} / \mathrm{kg}$ in pediatric patients (Table IV and V), agreeing with the value in adults which was reported by Fujiwara 
to be $41.61 / \mathrm{kg} .{ }^{12)}$ Furthermore, it was also suggested that pirarubicin was rapidly taken up and accumulated in tissue cells, based upon the results of the distribution rate constants (Table IV and V). The $t_{1 / 2(\alpha)}$ in adults reported by other investigators $^{9-13)}$ was $0.3-0.6 \mathrm{~h}$ and $t_{1 / 2(\beta)}$ was $13-14 \mathrm{~h}$, which is consistant with the values of the pediatric patients in this study. Therefore, it was revealed that there was no difference between the $t_{1 / 2} \mathrm{~s}$ in pediatric patients and adults.

The other pharmacokinetic parameters of pirarubicin in the pediatric patients of this study couldn't be compared with those reported previously in adults. ${ }^{9-12)}$ This was because there were very large variations in the adults pharmacokinetic parameters between reports. However, it appeared that the pharmacokinetics of pirarubicin in pediatric patients was fundamentally similar to that in adults. Consequently, the advantage of administering pirarubicin to pediatric patients might be that excessive peak concentrations of doxorubicin are avoided, thereby reducing the overall cardiotoxicity as in the case with adults. ${ }^{9)}$ It was suggested that there were large interindividual variations in the uptake of pirarubicin by blood cells, because large $\mathrm{CV}$ values were observed in all pharmacokinetic parameters, especially the $A U C_{0-24}$ ratio. Therefore, careful monitoring may be required in pediatric patients. In addition, it is necessary to investigate the uptake of pirarubicin by blood cells in more detail in order to clarify the reason for the interindividual variations.

Acknowledgement This work is supported in part by a Grant-in-Aid for Scientific Research (B) (No. 01921043) from the Ministry of Education, Science and Culture, Japan. We are greateful to Meiji Pharmaceutical Co., Ltd. and Kyowa Pharmaceutical Co., Ltd. for gifts of standard pirarubicin, daunorubicin hydrochloride and adriamycin hydrochloride, respectively.

\section{References}

1) H. Umezawa, Y. Takahashi, M. Kinoshita, H. Naganawa, T. Masuda, M. Ishizuka, K. Tatsuta and T. Takeuchi: Tetrahydropyranyl derivatives of daunomy- cin and adriamycin, J. Antibiot., 32, 1082-1084 (1979).

2) D. Dantchev, M. Paintrand, M. Hayat, C. Bourut and G. Mathé: Low heart and skin toxicity of a tetrahydropyranyl derivative of adriamycin (THP-ADM) as observed by electron and light microscopy, J. Antibiot., 32, $1085-1086$ (1979).

3) S. Kunimoto, K. Miura, Y. Takahashi, T. Takeuchi and H. Umezawa: Rapid uptake by cultured tumor cells and intracellular behavior of 4' - $O$-tetrahydropyranyl adriamycin, J. Antibiot., 36, 312-317 (1983).

4) H. Tapiero, J. N. Munck, M. Bennoun and G. Mathé: Differences in cellular uptake of adriamycin, THPadriamycin, and 4 '-epi-adriamycin in sensitive and ADM-resistant Friend leukemia cells: relationship with the cytotoxic activity, Proc. Am. Assoc. Cancer Res., 25, 307 (1984).

5) M. Ogawa, H. Miyamoto, J. Inagaki, N. Horikoshi, K. Ezaki, K. Inoue, K. Ikeda, N. Usui and H. Naka$\mathrm{da}$ : Phase I clinical trial of a new anthracycline, $4^{\prime}-O$ tetrahydropyranyladriamycin, Jpn. J. Cancer Chemother., 10, 129-133 (1983).

6) H. Majima: Exploratory clinical study of $4^{\prime}-O$ tetrahydropyranyl doxorubicin (THP-ADM), phase I, Jpn. J. Cancer Chemother., 10, 134-140 (1982).

7) A. Wakui, M. Yokoyama, K. Konno, Y. Nakai, T. Sakano, Y. Koyama, Y. Imamura, O. Nakajima, T. Niijima, H. Akaza, I. Kimura, T. Ohnoshi, S. Hiraki, T. Kato, H. Nishimura, J. Umezu and T. Saito: Phase I trial of 4'-O-tetrahydropyranyl-doxorubicin (THP), a multi-institutional cooperative study, Jpn. J. Cancer Chemother., 12, 118-124 (1985).

8) K. Okuma, I. Furuta and K. Ota: Acute cardiotoxicity of anthracyclines - analysis by using Holter ECG -, Jpn. J. Cancer Chemother., 11, 901-911 (1984).

9) A. A. Miller and C. G. Schmidt: Clinical pharmacology and toxicity of $4^{\prime}$ - $O$-tetrahydropyranyladriamycin, Cancer Chemother., 47, $1461-1465$ (1987).

10) H. Majima, H. Iguchi and H. Tone: Pharmacokinetic studies on THP-ADM (tetrahydropyranyl adriamycin), Jpn. J. Cancer Chemother., 13, 542-548 (1986).

11) O. Nakajima, Y. Imamura, A. Matsumoto, Y. Koyama, T. Shomura, K. Kawamura and S. Murata: Comparative studies on pharmacokinetics between THP and adriamycin in the same patients, Jpn. J. Cancer Chemother., 13, 542-548 (1986).

12) K. Fujiwara: Experimental and clinical studies on optimal administration schedule of $4^{\prime}-O$ tetrahydropyranyladriamycin for breast cancer, Keioigaku, 65, 147-162 (1988).

13) J. Robert, M. David, S. Huet, J. Chauvergue and A. Monnier: Pharmacocinetique de la pirarubicine (THPdoxorubicine) chez des malades cancereux, Bull. Cancer, 76, 889-892 (1989).

14) K. Yamaoka, Y. Tanigawara, T. Nakagawa and T. Uno: A pharmacokinetic analysis program (MULTI) for microcomputer, J. Pharmacobio-Dyn., 4, 879-885 (1981).

15) W. R. Crom, A. M. Glynn-Barnhart, J. H. Rodman, M. E. Tereshi, R. E. Kavanagh, M. L. Christensen, M. 
V. Relling and W. E. Evans: Pharmacokinetics of anticancer drugs in children, Clin. Pharmacokin., 12, $168-213$ (1987).

16) W. R. Crom, C. A. Raley, A. A. Green, F. A. Hayes, C. B. Pratt and W. E. Evans: Doxorubicin disposition in childhood and adolescents with cancer, Drug Intell. Clin. Pharm., 17, 448 (1983).

17) H. M. Pinedo, "Clinical pharmacology of antineoplastic drugs," Elsevier/North Holland Biochemical Press. B.V., Amsterdam, 1978, pp. 209-223. 